\title{
Quantitative and Qualitative Approach for IT Risk Assessment
}

\author{
Seong Ho Sung1), Pattan Zinna Khan²)
}

\begin{abstract}
Solid administration over every important partner is expected to set up a situation for the free and open exposure and examination of danger. The motivation behind Risk management is to distinguish potential issues before they happen so that hazard taking care of exercises may be arranged and summoned as required over the life of the item or venture to relieve unfavourable effects on accomplishing goals. Hazard administration is a consistent, forward-looking process that is an imperative piece of business and specialized administration forms. Hazard administration ought to address issues that could imperil accomplishment of basic goals. A ceaseless danger administration methodology is connected to successfully foresee and alleviate the dangers that have basic effect on the task. Successful danger administration incorporates early and forceful danger recognizable proof through the coordinated effort and inclusion of pertinent partners.
\end{abstract}

Keywords : Risk, Management, Distinguish, Imperil, Hazard.

\section{Introduction}

Solid administration over every important partner is expected to set up a situation for the free and open exposure and examination of danger[1].

Albeit specialized issues are an essential concern both right off the bat and all through all task stages, hazard administration must consider both inward and outer hotspots for expense, calendar, and specialized danger[2-4]. Early and forceful identification of danger is essential on the grounds that it is regularly less demanding, less immoderate, and less problematic to endeavor changes and right work endeavors amid the prior, instead of the later, periods of the undertaking[5-7]. Hazard administration can be separated into three sections: characterizing a danger administration system; recognizing and breaking down dangers; and taking care of distinguished dangers, including the execution of danger alleviation arranges when required.

Received(February 9, 2015), Review Result(1st: February 20, 2015, 2nd: March 9, 2015), Accepted(March 10, 2015)

${ }^{1}$ Department of Electronic Engineering, Gachon University

email: seongho@naver.com

${ }^{2}$ (Corresponding Author) Vidyaa Vikas Educational Institutions, Mysore - Bannur Road, Alanahally, Mysuru, Karnataka, India

email: pattanzinnakhan009@gmail.com 


\section{Risk Assessment}

\subsection{Notion of Risk}

Surveying the danger confronting a gathering of activities prompts a superior general perspective of danger to the portfolio. Taking a gander at the whole portfolio empowers individual activities to be looked at and comprehended as far as their danger. This aides in choice of tasks and centering of administration consideration on the ventures that most need it.Possibility is best set at a portfolio level. Despite the fact that not each task will experience the ill effects of danger, you realize that some will, however you don't know which ones. Administration holds for the portfolio can be set and attracted around adherence to the same standards as those talked about in the past segment[8-10]. Ventures in a portfolio regularly have interdependencies, shared assets, and shared objectives. In danger appraisal, they require not be considered in confinement. At the portfolio level, it is critical to express hazard emerging from undertaking interdependency. Hazard at the portfolio level can be shared and adjusted crosswise over activities as a method for relieving it.In rundown, hazard evaluation empowers you to better comprehend and deal with the portfolio in general. Primavera Risk Analysis-a full-lifecycle hazard examination arrangement incorporating cost and timetable danger administration - is the device that can convey these outcomes. Hazard Analysis gives a far reaching method for deciding certainty levels for task achievement, together with speedy and simple systems for deciding possibility and danger reaction arranges. It gives a target perspective of obliged possibility to represent cost and timetable vulnerability. What's more, it can investigate the expense adequacy of danger reaction arranges. Consolidated, these structure the premise of a danger balanced timetable, which is turning into the standard inside of the arranging and planning procedure. With Primavera Risk Analysis, your activities, portfolio, and business can profit from danger appraise.

\subsection{Data requirement and gathering}

Whatever the reasons, a large number of them include discernments about the procedure of faultless subjective danger appraisal that, for reasons likewise specified above, are much of the time not legitimate. Information are required for a danger appraisal, independent of whether subjective, semi quantitative or quantitative methodologies are utilized. Numerical information 
are favored, and an absence of proper critical information will influence all methodologies unfavorably. As information accumulation and documentation is typically the most tedious piece of the any danger appraisal, and solid rationale is required to integrate the information into an evaluation or determination concerning the danger, a subjective danger evaluation won't inexorably be snappier or more straightforward to finish. As a rule, subjective and semi-quantitative danger evaluations are speedier to finish, and, whilst they require an equivalent level of rationale and extensive numeracy, they require less particular scientific and computational assets. A subjective danger appraisal has depictions of the likelihood of an undesirable result in wording that are by their extremely nature subjective. It implies that it is not as a matter of course less demanding either for the danger chief to comprehend the conclusions got from the danger appraisal, or to disclose them to an outsider. Significant to any formal danger appraisal strategy is straightforwardness, whether to depict how a numerical or a subjective portrayal of danger wasa ccomplished, in light of the fact that this empowers clients to comprehend the premise of the evaluation, to comprehend its qualities and restrictions, to question or study the appraisal, or give extra information or learning to enhance the evaluation. Moreover, in light of the fact that all methodologies likewise require particular therapeutic, microbiological, organic, veterinary, epidemiological and other mastery, the incorporation of data and ideas from such a wide assortment of territories of information can make the danger appraisal less open.

\subsection{Risk assessment methods and methodologies}

Utilizing quantitative routines examiner stands before the issue of proper appraisal of qualities crucial for count. The estimation of danger can be given the utilization of a scales or specifically in the money related degree as anticipated measure of misfortunes joined with a given kind of danger, in expected period. Just sporadically happens that the group directing the procedure of IT danger evaluation had dependable information, taking into account acknowledgment of such errand precisely and with no mix-ups or issues. In addition for a few assets of benefits in association, misfortunes introduced in sums are hard to exact. It concerns e.g. loss of private data. Keeping in mind the end goal to set quality there ought to be characterized significance of data for legitimate acknowledgment of diverse business forms and theirs significance for working of hierarchical unit and as a result the entire endeavor, Basic relationship connected for IT hazard evaluation is exhibited as takes after:

$$
\mathrm{R}=\mathrm{P} \times \mathrm{W} \text { and } \mathrm{P}=\mathrm{F} \times \mathrm{V}
$$


Where:

R - Risk value,

P - Probability or predicted number of incident occurrence causing loss of assets value in defined period,

W - Value of loss - predicted medium loss of assets value, as a result of single incident occurrence,

F - Frequency of threat occurrence,

$\mathrm{V}$ - Susceptibility of Information system on (or its element) a threat; it is the measure of probability of usage of specified susceptibility by a given threat.

The Annualized Loss Expectancy (ALE) is the expected monetary loss that can be expected for an asset due to a risk over a one year period. It is defined as:

$$
\mathrm{ALE}=\mathrm{SLE} * \mathrm{ARO}
$$

where SLE is the Single Loss Expectancy and ARO is the Annualized Rate of Occurrence.A vital component of the Annualized Loss Expectancy is that it can be utilized specifically as a part of a money saving advantage examination.

\subsection{Qualitative solutions or outcomes}

There exist numerous subjective techniques for danger investigation. There will be examined the accompanying ones: FMEA/FMECA routines and NIST 800-30 and CRAMM procedures. FMEA (Failure Mode and Effects Analysis) and FMECA (Failure Mode and Effects Criticality Analysis) systems have theirs starting in 50s years of the most recent century, when they were expounded with the end goal of unwavering quality examination of weaponry and are utilized till now as a part of e.g. air ship industry, space and electronic industry. The substance of FMEA/FMECA is investigation of effect of every potential deformity on usefulness of the entire framework and request of potential imperfections as indicated by the level of its seriousness. FMECA strategy moreover presents examination of the level of deformity seriousness and analyzes whether it has basic character for usefulness of the entire assessed framework. Those strategies are very difficult, require learning and experience of persons who apply them, they are upheld with authority instruments, utilizing components of information designing and fluffy rationale. The procedure of IT danger appraisal as indicated by NIST SP 800-30 system is separated into 9 premise stages:

Selection of frameworks which are liable to assessment, 
Definition of the extent of assessment, accumulation of required data;

\subsection{Assumptions behind inferences and collection of data}

In spite of the fact that hazard appraisal comes in the last scene of our contextual analysis it really identifies with each phase of the business case. For instance any business case can be possibly crashed by changes in suspicions identified with the course of events or the monetary case. Such changes may be the consequence of an error on our part (ideally not!) or essentially as a result of changes in the more extensive environment (e.g. changes in expenses of materials or work or the non-accessibility of key specialized staff at basic focuses in the task.It is not your obligation in delivering the business case to foresee everything that can turn out badly or go astray from calendar. However your crowd won't get much certainty from your business case on the off chance that you have not expected the significant dangers to the task. In a perfect world, right off the bat you ought to recognize such dangers and group them as per that they are so prone to happen; how genuine they are; what the expenses of managing the results would be; and what the expenses of maintaining a strategic distance from or minimizing the danger are. You may require an alternate course of action to manage "most pessimistic scenario situations, for example, complete breakdown of the administration, which may take the type of calamity recuperation arranging.

\subsection{Critical Assumptions}

Basic suppositions include anything that may be taken as a "given" for a specific undertaking. For instance an Institutional Repository task may require that we will have prepared access to registering specialized staff at basic crossroads of the venture. Obviously if such get to is not inevitable then we will confront disturbances to the Implementation Timeline.

\subsection{Risk Assessment}

Conversely, Risks include anything that may turn out badly with the task. Normally these are evaluated for both seriousness and probability. The resultant grid (Low hazard low probability; Low hazard high probability; High hazard low probability; High hazard high probability) offers the venture some assistance with teaming to organize systems for reckoning 
the danger or minimizing its belongings if it happen.

In writing up our business case for an Institutional Repository we might identify selected Assumptions and Risks as follows: Information Technology staff and Application Development staff will be available to work in developing the Repository as needed

- Following a successful pilot money will be made available to purchase a dedicated server

- Affected staff will take the time to test the system and provide feedback

- The system may not deliver on its promise

- Being Open Source software a technical glitch may take some time to find a solution

- The system may not be able to handle the demand placed upon it.

\section{Conclusion and Recommendations}

As we mentioned in our Introduction to the Case Study the substantive content that we have examined on a day-by-day basis over the last five Briefings is usually completed by a brief Conclusion with Recommendations. As our recommended further reading illustrates this does not have to be a lengthy piece of writing.

Typically it will follow the format:

- The benefits of the system outweigh the costs and the risks

- The organization should go ahead with the purchase

- Benefits of FMECA (Failure Mode and Effects Criticality Analysis)

- It assists communication between main contractor and suppliers who work more closely during the concept.

\section{References}

[1] E. I. Szczepankiewicz and P. Szczepankiewicz, Risk analysis in the IT environment for the purpose of operational risk management. Part 2 - Risk assessment stage (In Polish), Monitor Rachunkowoscii Finansow, Magazine no.7 (2006).

[2] A. Galach, Instruction of IT system security management (In Polish), Osrodek Doradztwa i Doskonalenia Kadr Publishing House, Gdansk (2004).

[3] E. Schechter, Computer Security Strength \& Risk: A Quantitative Approach. Harvard University, Cambridge, Massachusetts, USA (2004). 
[4] Z. Szyjewski, Methodologies of IT projects management (In Polish), Placet, Warsaw (2004).

[5] K. J. S. Hoo, How Much Is Enough? A Risk-Management Approach to Computer Security, Doctoral thesis, Stanford University, (2000).

[6] M. Ryba, Analysis and management of Information Systems risk (In Polish), Ernst \& Young (2005).

[7] Z. Szyjewski, Methodologies of IT projects management (In Polish), Placet, Warsaw (2004).

[8] DC White Consulting Engineer, http://www.dcwhite.co.uk, April 2 (2014).

[9] United States Department of Defense, https://www.defense.gov/, April 2 (2014).

[10] E. Reich, A. Lussi and E. Newbrun, Caries-risk assessment, International Dental Journal, (1999), Vol.49, No.1, pp.15-26. 